\title{
Strong convergence of a hybrid projection iterative algorithm for common solutions of operator equations and of inclusion problems
}

\author{
Changqun $\mathrm{Wu}^{1 *}$ and Aichao $\mathrm{Liu}^{2}$
}

\author{
* Correspondence: \\ kyls2003@yahoo.com.cn \\ ${ }^{1}$ School of Business and \\ Administration, Henan University, \\ Kaifeng 45000, China \\ Full list of author information is \\ available at the end of the article
}

\begin{abstract}
In this article, zero points of the sum of a maximal monotone operator and an inverse-strongly monotone mapping, solutions of a monotone variational inequality, and fixed points of a strict pseudocontraction are investigated. A hybrid projection iterative algorithm is considered for analyzing the convergence of the iterative sequences. Strong convergence theorems are established in the framework of real Hilbert spaces without any compact assumptions. Some applications of the main results are also provided.
\end{abstract}

AMS Classification: 47H05; 47H09; 47J25; $90 \mathrm{C} 33$.

Keywords: fixed point, monotone operator, strict pseudocontraction, variational inequality, zero point

\section{Introduction}

The theory of monotone operators has emerged as an effective and powerful tool for studying a wide class of unrelated problems arising in various branches of social, engineering, and pure sciences in unified and general framework. Two notions related to monotone operators have turned out to be very useful in the study of various problems involving such operators. The first one, which is inspired by the notion of subdifferential of a convex function, is the concept of enlargement of a given operator; see [1-3] and the references therein. It allows to make a quantitative analysis in different problems involving monotone operators, like for example variational inequalities, inclusions, etc. The second notion is the one of generalized sum of two monotone operators; see $[4,5]$ and the references therein. In recent years, much attention has been given to develop efficient numerical methods for treating zero point problems of monotone operators and fixed point problems of mappings which are Lipschitz continuous; see [6-28] and the references therein. The gradient-projection method is a powerful tool for solving constrained convex optimization problems and has extensively been studied; see [29-31] and the references therein. It has recently applied to solve split feasibility problems which find applications in image reconstructions and the intensity modulated radiation theory; see [32-35] and the reference therein.

In this article, zero points of the sums of a maximal monotone operator and an inverse-strongly monotone mapping, solutions of a monotone variational inequality,

(C) 2012 Wu and Liu; licensee Springer. This is an Open Access article distributed under the terms of the Creative Commons Attribution License (http://creativecommons.org/licenses/by/2.0), which permits unrestricted use, distribution, and reproduction in any medium, provided the original work is properly cited. 
and fixed points of a strict pseudocontraction are investigated based on a hybrid iterative method.

The organization of this article is as follows. In Section 2, we provide some necessary preliminaries. In Section 3, a hybrid iterative method is proposed and analyzed. Strong convergence theorems for common elements in the zero point set of the sums of a maximal monotone operator and an inverse-strongly monotone mapping, the solution set of a monotone variational inequality, and the fixed point set of a strict pseudocontraction are established in the framework of real Hilbert spaces without any compact assumptions. In Section 4, applications of the main results are discussed.

\section{Preliminaries}

In what follows, we always assume that $H$ is a real Hilbert space with inner product $\langle\cdot$, $\cdot>$ and norm $\|\cdot\|$. Let $C$ be a nonempty, closed, and convex subset of $H$. Let $S: C \rightarrow$ $C$ be a nonlinear mapping. $F(S)$ stands for the fixed point set of $S$; that is, $F(S):=\{x \in$ $C: x=T x\}$.

Recall that $S$ is said to be nonexpansive iff

$$
\|S x-S y\| \leq\|x-y\|, \quad \forall x, y \in C .
$$

If $C$ is a bounded, closed, and convex subset of $H$, then $F(S)$ is not empty, closed, and convex; see [36].

$S$ is said to be $\kappa$-strictly pseudocontractive iff there exists a constant $\kappa \in[0,1)$ such that

$$
\|S x-S y\|^{2} \leq\|x-y\|^{2}+\kappa\|x-S x-y+S y\|^{2}, \quad \forall x, y \in C .
$$

It is clear that the class of $\kappa$-strictly pseudocontractive mappings includes the class of non-

expansive mappings.

Let $A: C \rightarrow H$ be a mapping. $A$ is said to be monotone iff

$$
\langle A x-A y, x-y\rangle \geq 0, \quad \forall x, y \in C .
$$

$A$ is said to be inverse-strongly monotone iff there exists a constant $\alpha>0$ such that

$$
\langle A x-A y, x-y\rangle \geq \alpha\|A x-A y\|^{2}, \quad \forall x, y \in C .
$$

For such a case, $A$ is also said to be $\alpha$-inverse-strongly monotone.

$A$ is said to be Lipschitz continuous iff there exists a positive constant $L$ such that

$$
\|A x-A y\| \leq L\|x-y\|, \quad \forall x, y \in C .
$$

Recall that the classical variational inequality is to find an $x \in C$ such that

$$
\langle A x, y-x\rangle \geq 0, \quad \forall y \in C .
$$

It is known that $x \in C$ is a solution to (2.1) if and only if $x$ is a fixed point of the mapping $\operatorname{Proj}_{C}(I-r A)$, where $r>0$ is a constant, $I$ stands for the identity mapping, and $\operatorname{Proj}_{C}$ stands for the metric projection from $H$ onto $C$. If $A$ is $\alpha$-inverse-strongly monotone and $r \in(0,2 \alpha]$, then the mapping $\operatorname{Proj}_{C}(I-r A)$ is nonexpansive; see [37] for more details. It follows that $V I(C, A)$, where $V I(C, A)$ stands for the solution set of (2.1), is closed and convex. 
A set-valued mapping $R: H \rightrightarrows H$ is said to be monotone iff, for all $x, y \in H, f \in R x$ and $g \in R y$ imply $\langle x-y, f-g\rangle>0$. A monotone mapping $R: H \rightrightarrows H$ is maximal iff the graph $G(R)$ of $R$ is not properly contained in the graph of any other monotone mapping. It is known that a monotone mapping $R$ is maximal if and only if, for any $(x, f)$ $\in H \times H,\langle x-y, f-g\rangle \geq 0$, for all $(y, g) \in G(R)$ implies $f \in R x$.

The class of monotone operators is one of the most important classes of operators. Within the past several decades, many authors have been devoting to the studies on the existence and convergence of zero points for maximal monotone operators; see [38-45] and the references therein. For a maximal monotone operator $M$ on $H$ and $r$ $>0$, we may define the single-valued resolvent $J_{r}: H \rightarrow D(M)$, where $D(M)$ denotes the domain of $M$. It is known that $J_{r}$ is firmly nonexpansive and $M^{-1}(0)=F\left(J_{r}\right)$, where $F\left(J_{r}\right):=\left\{x \in D(M): x=J_{r} x\right\}$, and $M^{-1}(0):\{x \in H: 0 \in M x\}$.

In this article, zero points of the sums of a maximal monotone operator and an inverse-strongly monotone mapping, solutions of a monotone variational inequality, and fixed points of a strict pseudocontraction are investigated. A hybrid iterative algorithm is considered for analyzing the convergence of iterative sequences. Strong convergence theorems are established in the framework of real Hilbert spaces without any compact assumptions.

In order to prove our main results, we also need the following definitions and lemmas.

Lemma 2.1 [46]. Let $C$ be a nonempty, closed, and convex subset of $H$, and $S: C \rightarrow$ $C$ a $\kappa$-strict pseudocontraction. Define a mapping $S_{\alpha} x=\beta x+(1-\beta) S x$ for all $x \in C$. If $\beta \in[\kappa, 1)$, then the mapping $S_{\beta}$ is a nonexpansive mapping such that $F\left(S_{\beta}\right)=F(S)$.

Lemma 2.2 [47]. Let $C$ be a nonempty, closed, and convex subset of $H$. Let $S: C \rightarrow C$ be a nonexpansive mapping. Then the mapping $I-S$ is demiclosed at zero, that is, if $\left\{x_{n}\right\}$ is a sequence in $C$ such that $x_{n} \rightarrow \bar{x}$ and $x_{n}-S x_{n} \rightarrow 0$, then $\bar{x} \in F(S)$.

Lemma 2.3. Let $C$ be a nonempty, closed, and convex subset of $H, B: C \rightarrow H$ a mapping, and $M: H \rightrightarrows H$ a maximal monotone operator. Then $F\left(J_{r}(I-s B)\right)=(B+M)^{-1}(0)$.

Proof. Notice that

$$
\begin{aligned}
p \in F\left(J_{r}(I-s B)\right) & \Leftrightarrow p=J_{r}(I-s B) p \Leftrightarrow p-s B p \in p+s M p \\
& \Leftrightarrow 0 \in(B+M)^{-1}(0) \Leftrightarrow p \in(B+M)^{-1}(0) .
\end{aligned}
$$

This completes the proof.

Lemma 2.4 [48]. Let $C$ be a nonempty, closed, and convex subset of $H, A: C \rightarrow H a$ Lipschitz monotone mapping, and $N_{C} x$ the normal cone to $C$ at $x \in C$; that is, $N_{C} x=$ $\{y \in H:\langle x-u, y\rangle, \forall u \in C\}$. Define

$$
W x= \begin{cases}A x+N_{C} x, & x \in C, \\ \varnothing & x \notin C .\end{cases}
$$

Then $W$ is maximal monotone and $0 \in W x$ if and only if $x \in V I(C, A)$.

\section{Main results}

Now, we are in a position to give our main results.

Theorem 3.1. Let $C$ be a nonempty, closed, and convex subset of $H$. Let $S: C \rightarrow C$ be a $\kappa$-strict pseudocontraction with a nonempty fixed point set, $A: C \rightarrow H$ an $\alpha$-inversestrongly monotone mapping, and $B: C \rightarrow H$ a $\beta$-inverse-strongly monotone mapping. 
Let $M: H \rightrightarrows H$ be a maximal monotone operator such that $D(M) \subset C$. Assume that $\mathcal{F}:=F(S) \cap(B+M)^{-1}(0) \cap \operatorname{VI}(C, A)$ is not empty. Let $\left\{x_{n}\right\}$ be a sequence generated by the following iterative process:

$$
\left\{\begin{array}{l}
x_{1} \in C \\
C_{1}=C \\
z_{n}=\operatorname{Proj}_{C}\left(J_{s_{n}}\left(x_{n}-s_{n} B x_{n}\right)-r_{n} A J_{s_{n}}\left(x_{n}-s_{n} B x_{n}\right)\right), \\
y_{n}=\alpha_{n} x_{n}+\left(1-\alpha_{n}\right)\left(\beta_{n} z_{n}+\left(1-\beta_{n}\right) S z_{n}\right) \\
C_{n+1}=\left\{v \in C_{n}:\left\|y_{n}-v\right\| \leq\left\|x_{n}-v\right\|\right\} \\
x_{n+1}=\operatorname{Proj}_{C_{n+1}} x_{1}, \quad n \geq 0
\end{array}\right.
$$

where $J_{s_{n}}=\left(I+s_{n} M\right)^{-1},\left\{r_{n}\right\}$ is a sequence in $(0,2 \alpha),\left\{s_{n}\right\}$ is a sequence in $(0,2 \beta)$, and $\left\{\alpha_{n}\right\}$ and $\left\{\beta_{n}\right\}$ are sequences in $(0,1)$. Assume that the following restrictions are satisfied

(a) $0 \leq \alpha_{n} \leq a<1, \kappa \leq \beta_{n} \leq b<1$;

(b) $0<r \leq r_{n} \leq r^{\prime}<2 \alpha$;

(c) $0<s \leq s_{n} \leq s^{\prime}<2 \beta$,

where $a, b, r, r, s$, and s' are real constants. Then the sequence $\left\{x_{n}\right\}$ converges strongly to $\operatorname{Proj}_{\mathcal{F}} x_{1}$.

Proof. First, we show that $C_{n}$ is closed and convex for each $n \geq 1$. From the assumption, we see that $C_{1}=C$ is closed and convex. Suppose that $C_{m}$ is closed and convex for some $m \geq 1$. We show that $C_{m+1}$ is closed and convex for the same $m$. Let $v_{1}, v_{2} \in$ $C_{m+1}$ and $v=t v_{1}+(1-t) v_{2}$, where $t \in(0,1)$. Notice that

$$
\left\|y_{m}-v\right\| \leq\left\|x_{m}-v\right\|
$$

is equivalent to

$$
\left\|y_{m}\right\|^{2}-\left\|x_{m}\right\|^{2}-2\left\langle v, y_{m}-x_{m}\right\rangle \geq 0 .
$$

It is clearly to see that $v \in C_{m+1}$. This shows that $C_{n}$ is closed and convex for each $n$ $\geq 1$. Put

$$
v_{n}=J_{s_{n}}\left(x_{n}-s_{n} B x_{n}\right),
$$

and

$$
u_{n}=S_{n} z_{n},
$$

where $S_{n}$ is defined by

$$
S_{n} x=\beta_{n} x+\left(1-\beta_{n}\right) S x, \quad \forall x \in C .
$$

We see from Lemma 2.1 that $S_{n}$ is nonexpansive with $F\left(S_{n}\right)=F(S)$. Since $A$ is $\alpha$ inverse-strongly monotone, and $B$ is $\beta$-inverse-strongly monotone, we see from the restriction (b) that

$$
\begin{aligned}
\left\|\left(x-r_{m} A x\right)-\left(y-r_{m} A y\right)\right\|^{2}= & \|x-y\|^{2}-2 r_{m}\langle x-y, A x-A y\rangle+r_{m}^{2} m\|A x-A y\|^{2} \\
& \leq\|x-y\|^{2}-r_{m}\left(2 \alpha-r_{m}\right)\|A x-A y\|^{2} \\
& \leq\|x-y\|^{2}, \quad \forall x, y \in C,
\end{aligned}
$$


and

$$
\begin{aligned}
\left\|\left(I-s_{m} B\right) x-\left(I-s_{m} B\right) y\right\|^{2} & =\|x-y\|^{2}-2 s_{m}\langle x-y, B x-B y\rangle+s_{m}^{2}\|B x-B y\|^{2} \\
& \leq\|x-y\|^{2}-s_{m}\left(2 \beta-s_{m}\right)\|B x-B y\|^{2} \\
& \leq\|x-y\|^{2}, \quad \forall x, \quad y \in C .
\end{aligned}
$$

Now, we show that $\mathcal{F} \subset C_{n}$ for each $n \geq 1$. Notice that $\mathcal{F} \subset C=C_{1}$. Suppose that $\mathcal{F} \subset C_{m}$ for some $m \geq 1$. For any $p \in \mathcal{F} \subset C_{m}$, we see from (3.2), and (3.3) that

$$
\begin{aligned}
\left\|y_{m}-p\right\| & \leq \alpha_{m}\left\|x_{m}-p\right\|+\left(1-\alpha_{m}\right)\left\|u_{m}-p\right\| \\
& \leq \alpha_{m}\left\|x_{m}-p\right\|+\left(1-\alpha_{m}\right)\left\|z_{m}-p\right\| \\
& \leq \alpha_{m}\left\|x_{m}-p\right\|+\left(1-\alpha_{m}\right)\left\|\left(v_{m}-r_{m} A v_{m}\right)-\left(p-r_{m} A p\right)\right\| \\
& \leq \alpha_{m}|| x_{m}-p\left\|+\left(1-\alpha_{m}\right)\right\|\left(x_{m}-s_{m} B x_{m}\right)-\left(p-s_{m} B p\right) \| \\
& \leq \alpha_{m}|| x_{m}-p\left\|+\left(1-\alpha_{m}\right)\right\| x_{m}-p \| \\
& =\left\|x_{m}-p\right\| .
\end{aligned}
$$

This shows that $p \in C_{m+1}$. This proves that $\mathcal{F} \subset C_{n}$. Note that $x_{n}=\operatorname{Proj}_{C_{n}} x_{1}$. For each $p \in \mathcal{F} \subset C_{n}$, we have $\left\|x_{1}-x_{n}\right\| \leq\left\|x_{1}-p\right\|$. Since $B$ is inverse-strongly monotone, we see from Lemma 2.3 that $(B+M)^{-1}(0)$ is closed, and convex. Since $A$ is Lipschitz continuous, we find that $\operatorname{VI}(C, A)$ is close, and convex. In view of Lemma 2.2, we obtain $F(S)$ is closed, and convex. This proves that $\mathcal{F}$ is closed and convex. It follows that

$$
\left\|x_{1}-x_{n}\right\| \leq\left\|x_{1}-\operatorname{Proj}_{\mathcal{F}} x_{1}\right\|
$$

This implies that $\left\{x_{n}\right\}$ is bounded. Since $x_{n}=\operatorname{Proj}_{C_{n}} x_{1}$ and $x_{n+1}=\operatorname{Proj}_{C_{n+1}} x_{1} \in C_{n+1} \subset C_{n}$, we have

$$
\begin{aligned}
0 & \leq\left\langle x_{1}-x_{n}, x_{n}-x_{n+1}\right\rangle \\
& =\left\langle x_{1}-x_{n}, x_{n}-x_{1}+x_{1}-x_{n+1}\right\rangle \\
& \leq-\left\|x_{1}-x_{n}\right\|^{2}+\left\|x_{1}-x_{n}\right\|\left\|x_{1}-x_{n+1}\right\| .
\end{aligned}
$$

It follows that

$$
\left\|x_{n}-x_{1}\right\| \leq\left\|x_{n+1}-x_{1}\right\|
$$

This proves that $\lim _{n \rightarrow \infty}\left\|x_{n}-x_{1}\right\|$ exists. Notice that

$$
\begin{aligned}
& \left\|x_{n}-x_{n+1}\right\|^{2} \\
& =\left\|x_{n}-x_{1}\right\|^{2}+2\left\langle x_{n}-x_{1}, x_{1}-x_{n+1}\right\rangle+\left\|x_{1}-x_{n+1}\right\|^{2} \\
& =\left\|x_{n}-x_{1}\right\|^{2}-2\left\|x_{n}-x_{1}\right\|^{2}+2\left\langle x_{n}-x_{1}, x_{n}-x_{n+1}\right\rangle+\left\|x_{1}-x_{n+1}\right\|^{2} \\
& \leq\left\|x_{1}-x_{n+1}\right\|^{2}-\left\|x_{n}-x_{1}\right\|^{2} .
\end{aligned}
$$

It follows that

$$
\lim _{n \rightarrow \infty}\left\|x_{n}-x_{n+1}\right\|=0 .
$$

In view of $x_{n+1}=\operatorname{Proj}_{C_{n+1}} x_{1} \in C_{n+1}$, we see that

$$
\left\|y_{n}-x_{n+1}\right\| \leq\left\|x_{n}-x_{n+1}\right\| \text {. }
$$


This implies that

$$
\left\|y_{n}-x_{n}\right\| \leq\left\|y_{n}-x_{n+1}\right\|+\left\|x_{n}-x_{n+1}\right\| \leq 2\left\|x_{n}-x_{n+1}\right\| .
$$

We, therefore, obtain from (3.6) that

$$
\lim _{n \rightarrow \infty}\left\|x_{n}-y_{n}\right\|=0
$$

On the other hand, we see from (3.3) that

$$
\begin{aligned}
\left\|y_{n}-p\right\|^{2} & \leq \alpha_{n}\left\|x_{n}-p\right\|^{2}+\left(1-\alpha_{n}\right)\left\|u_{n}-p\right\|^{2} \\
& \leq \alpha_{n}\left\|x_{n}-p\right\|^{2}+\left(1-\alpha_{n}\right)\left\|z_{n}-p\right\|^{2} \\
& \leq \alpha_{n}\left\|x_{n}-p\right\|^{2}+\left(1-\alpha_{n}\right)\left\|v_{n}-p\right\|^{2} \\
& =\alpha_{n}\left\|x_{n}-p\right\|^{2}+\left(1-\alpha_{n}\right)\left\|J_{s_{n}}\left(x_{n}-s_{n} B x_{n}\right)-J_{s_{n}}\left(p-s_{n} B p\right)\right\|^{2} \\
& \leq\left\|x_{n}-p\right\|^{2}-\left(1-\alpha_{n}\right) s_{n}\left(2 \beta-s_{n}\right)\left\|B x_{n}-B p\right\|^{2} .
\end{aligned}
$$

It follows that

$$
\begin{aligned}
\left(1-\alpha_{n}\right) s_{n}\left(2 \beta-s_{n}\right)\left\|B x_{n}-B p\right\|^{2} & \leq\left\|x_{n}-p\right\|^{2}-\left\|y_{n}-p\right\|^{2} \\
& \leq\left\|x_{n}-y_{n}\right\|\left(\left\|x_{n}-p\right\|+\left\|y_{n}-p\right\|\right) .
\end{aligned}
$$

In view of the restrictions (a), and (c), we find from (3.7) that

$$
\lim _{n \rightarrow \infty}\left\|B x_{n}-B p\right\|=0 \text {. }
$$

Since $J_{s_{n}}$ is firmly nonexpansive, we find that

$$
\begin{aligned}
&\left\|v_{n}-p\right\|^{2}=\left\|J_{s_{n}}\left(x_{n}-s_{n} B x_{n}\right)-J_{s_{n}}\left(p-s_{n} B p\right)\right\|^{2} \\
& \leq\left\langle v_{n}-p,\left(x_{n}-s_{n} B x_{n}\right)-\left(p-s_{n} B p\right)\right\rangle \\
&= \frac{1}{2}\left(\left\|v_{n}-p\right\|^{2}+\left\|\left(x_{n}-s_{n} B x_{n}\right)-\left(p-s_{n} B p\right)\right\|^{2}\right. \\
&\left.\quad-\left\|\left(v_{n}-p\right)-\left(\left(x_{n}-s_{n} B x_{n}\right)-\left(p-s_{n} B p\right)\right)\right\|^{2}\right) \\
& \leq \frac{1}{2}\left(\left\|v_{n}-p\right\|^{2}+\left\|x_{n}-p\right\|^{2}-\left\|v_{n}-x_{n}+s_{n}\left(B x_{n}-B p\right)\right\|^{2}\right) \\
&= \frac{1}{2}\left(\left\|v_{n}-p\right\|^{2}+\left\|x_{n}-p\right\|^{2}-\left\|v_{n}-x_{n}\right\|^{2}-s_{n}^{2}\left\|B x_{n}-B p\right\|^{2}\right. \\
&\left.-2 s_{n}\left\langle v_{n}-x_{n}, B x_{n}-B p\right\rangle\right) \\
& \leq \frac{1}{2}\left(\left\|v_{n}-p\right\|^{2}+\left\|x_{n}-p\right\|^{2}-\left\|v_{n}-x_{n}\right\|^{2}+2 s_{n}\left\|v_{n}-x_{n}\right\|\left\|B x_{n}-B p\right\|\right) .
\end{aligned}
$$

This finds that

$$
\left\|v_{n}-p\right\|^{2} \leq\left\|x_{n}-p\right\|^{2}-\left\|v_{n}-x_{n}\right\|^{2}+2 s_{n}\left\|v_{n}-x_{n}\right\|\left\|B x_{n}-B p\right\| .
$$

It follows from (3.1) that

$$
\begin{aligned}
\left\|y_{n}-p\right\|^{2} & \leq \alpha_{n}\left\|x_{n}-p\right\|^{2}+\left(1-\alpha_{n}\right)\left\|u_{n}-p\right\|^{2} \\
& \leq\left\|x_{n}-p\right\|^{2}-\left(1-\alpha_{n}\right)\left\|v_{n}-x_{n}\right\|^{2}+2 s_{n}\left\|v_{n}-x_{n}\right\|\left\|B x_{n}-B p\right\|
\end{aligned}
$$

which in turn implies that

$$
\begin{aligned}
\left(1-\alpha_{n}\right)\left\|v_{n}-x_{n}\right\|^{2} & \leq\left\|x_{n}-p\right\|^{2}-\left\|y_{n}-p\right\|^{2}+2 s_{n}\left\|v_{n}-x_{n}\right\|\left\|B x_{n}-B p\right\| \\
& \leq\left\|x_{n}-y_{n}\right\|\left(\left\|x_{n}-p\right\|+\left\|y_{n}-p\right\|\right)+2 s_{n}\left\|v_{n}-x_{n}\right\|\left\|B x_{n}-B p\right\| .
\end{aligned}
$$


In view of the restriction (a), we see from (3.7), and (3.8) that

$$
\lim _{n \rightarrow \infty}\left\|v_{n}-x_{n}\right\|=0
$$

On the other hand, we see from (3.2) that

$$
\begin{aligned}
\left\|y_{n}-p\right\|^{2} & \leq \alpha_{n}\left\|x_{n}-p\right\|^{2}+\left(1-\alpha_{n}\right)\left\|u_{n}-p\right\|^{2} \\
& \leq \alpha_{n}\left\|x_{n}-p\right\|^{2}+\left(1-\alpha_{n}\right)\left\|\left(v_{n}-r_{n} A v_{n}\right)-\left(p-r_{n} A p\right)\right\|^{2} \\
& \leq\left\|x_{n}-p\right\|^{2}-\left(1-\alpha_{n}\right) r_{n}\left(2 \alpha-r_{n}\right)\left\|A v_{n}-A p\right\|^{2}
\end{aligned}
$$

It follows that

$$
\begin{aligned}
\left(1-\alpha_{n}\right) r_{n}\left(2 \alpha-r_{n}\right)\left\|A v_{n}-A p\right\|^{2} & \leq\left\|x_{n}-p\right\|^{2}-\left\|y_{n}-p\right\|^{2} \\
& \leq\left\|x_{n}-y_{n}\right\|\left(\left\|x_{n}-p\right\|+\left\|y_{n}-p\right\|\right) .
\end{aligned}
$$

In view of the restrictions (a), and (b), we find from (3.7) that

$$
\lim _{n \rightarrow \infty}\left\|A v_{n}-A p\right\|=0 \text {. }
$$

Since $\operatorname{Proj}_{C}$ is firmly nonexpansive, we arrive at

$$
\begin{aligned}
\left\|z_{n}-p\right\|^{2}= & \left\|\operatorname{Proj}_{C}\left(v_{n}-r_{n} A v_{n}\right)-\operatorname{Proj}_{C}\left(p-r_{n} A p\right)\right\|^{2} \\
\leq & \left\langle z_{n}-p,\left(v_{n}-r_{n} A v_{n}\right)-\left(p-r_{n} A p\right)\right\rangle \\
= & \frac{1}{2}\left(\left\|z_{n}-p\right\|^{2}+\left\|\left(v_{n}-r_{n} A v_{n}\right)-\left(p-r_{n} A p\right)\right\|^{2}\right. \\
& \left.-\left\|\left(z_{n}-p\right)-\left(\left(v_{n}-r_{n} A v_{n}\right)-\left(p-r_{n} A p\right)\right)\right\|^{2}\right) \\
\leq & \frac{1}{2}\left(\left\|z_{n}-p\right\|^{2}+\left\|x_{n}-p\right\|^{2}-\left\|z_{n}-v_{n}+r_{n}\left(A v_{n}-A p\right)\right\|^{2}\right) \\
= & \frac{1}{2}\left(\left\|z_{n}-p\right\|^{2}+\left\|x_{n}-p\right\|^{2}-\left\|z_{n}-v_{n}\right\|^{2}-r_{n}^{2}\left\|A v_{n}-A p\right\|^{2}\right. \\
& \left.-2 r_{n}\left\langle z_{n}-v_{n}, A v_{n}-r p\right\rangle\right) \\
\leq & \frac{1}{2}\left(\left\|z_{n}-p\right\|^{2}+\left\|x_{n}-p\right\|^{2}-\left\|z_{n}-v_{n}\right\|^{2}+2 r_{n}\left\|z_{n}-v_{n}\right\|\left\|A v_{n}-A p\right\|\right)
\end{aligned}
$$

which finds that

$$
\left\|z_{n}-p\right\|^{2} \leq\left\|x_{n}-p\right\|^{2}-\left\|z_{n}-v_{n}\right\|^{2}+2 r_{n}\left\|z_{n}-v_{n}\right\|\left\|A v_{n}-A p\right\| .
$$

This implies that

$$
\begin{aligned}
\left\|y_{n}-p\right\|^{2} & \leq \alpha_{n}\left\|x_{n}-p\right\|^{2}+\left(1-\alpha_{n}\right)\left\|u_{n}-p\right\|^{2} \\
& \leq\left\|x_{n}-p\right\|^{2}-\left(1-\alpha_{n}\right)\left\|z_{n}-v_{n}\right\|^{2}+2 r_{n}\left\|z_{n}-v_{n}\right\|\left\|A v_{n}-A p\right\|
\end{aligned}
$$

It follows that

$$
\begin{aligned}
\left(1-\alpha_{n}\right)\left\|z_{n}-v_{n}\right\|^{2} & \leq\left\|x_{n}-p\right\|^{2}-\left\|y_{n}-p\right\|^{2}+2 r_{n}\left\|z_{n}-v_{n}\right\|\left\|A x_{n}-A p\right\| \\
& \leq\left\|x_{n}-y_{n}\right\|\left(\left\|x_{n}-p\right\|+\left\|y_{n}-p\right\|\right)+2 r_{n}\left\|z_{n}-v_{n}\right\|\left\|A x_{n}-A p\right\| .
\end{aligned}
$$

In view of the restriction (a), we see from (3.7), and (3.11) that

$$
\lim _{n \rightarrow \infty}\left\|z_{n}-v_{n}\right\|=0
$$


On the other hand, we have

$$
\left\|x_{n}-y_{n}\right\|=\left\|x_{n}-\alpha_{n} x_{n}-\left(1-\alpha_{n}\right) S_{n} z_{n}\right\|=\left(1-\alpha_{n}\right)\left\|x_{n}-S_{n} z_{n}\right\| .
$$

In view of (3.7), we see from the restriction (a) that

$$
\lim _{n \rightarrow \infty}\left\|x_{n}-S_{n} z_{n}\right\|=0 .
$$

Note that

$$
\left\|z_{n}-x_{n}\right\| \leq\left\|z_{n}-v_{n}\right\|+\left\|v_{n}-x_{n}\right\| .
$$

It follows from (3.10) and (3.13) that

$$
\lim _{n \rightarrow \infty}\left\|z_{n}-x_{n}\right\|=0
$$

In view of

$$
\begin{aligned}
\left\|x_{n}-S_{n} x_{n}\right\| & \leq\left\|S_{n} x_{n}-S_{n} z_{n}\right\|+\left\|S_{n} z_{n}-x_{n}\right\| \\
& \leq\left\|x_{n}-z_{n}\right\|+\left\|S_{n} z_{n}-x_{n}\right\|,
\end{aligned}
$$

we see from (3.14) and (3.15) that

$$
\lim _{n \rightarrow \infty}\left\|x_{n}-S_{n} x_{n}\right\|=0 .
$$

Note that

$$
\begin{aligned}
\left\|S x_{n}-x_{n}\right\| & \leq\left\|S x_{n}-S_{n} x_{n}\right\|+\left\|S_{n} x_{n}-x_{n}\right\| \\
& \leq \beta_{n}\left\|S x_{n}-x_{n}\right\|+\left\|S_{n} x_{n}-x_{n}\right\|,
\end{aligned}
$$

which yields that

$$
\left(1-\beta_{n}\right)\left\|S x_{n}-x_{n}\right\| \leq\left\|S_{n} x_{n}-x_{n}\right\| .
$$

In view of the restriction (b), we conclude from (3.16) that

$$
\lim _{n \rightarrow \infty}\left\|S x_{n}-x_{n}\right\|=0
$$

Since $\left\{x_{n}\right\}$ is bounded, there exists a subsequence $\left\{x_{n_{i}}\right\}$ of $\left\{x_{n}\right\}$ such that $x_{n_{i}} \rightarrow q$. In view of Lemma 2.2, we obtain from (3.17) that $q \in F(S)$. In view of (3.10), and (3.15), we see that $u_{n_{i}} \rightarrow q$, and $z_{n_{i}} \rightarrow q$, respectively. Now, we are in a position to show that $q \in V I(C, A)$.

Define

$$
W x=\left\{\begin{array}{lr}
A x+N_{C} x, & x \in C, \\
\emptyset, & x \notin C .
\end{array}\right.
$$

Then $W$ is maximal monotone. Let $(x, y) \in G(W)$. Since $y-A x \in N_{C} x$ and $z_{n} \in C$, we have

$$
\left\langle x-z_{n}, y-A x\right\rangle \geq 0 .
$$

On the other hand, we have from $z_{n}=\operatorname{Proj}_{C}\left(I-r_{n} A_{1}\right) v_{n}$ that

$$
\left\langle x-z_{n}, z_{n}-\left(I-r_{n} A\right) v_{n}\right\rangle \geq 0
$$


and hence

$$
\left\langle x-z_{n}, \frac{z_{n}-v_{n}}{r_{n}}+A v_{n}\right\rangle \geq 0 .
$$

It follows that

$$
\begin{aligned}
\left\langle x-z_{n_{i}}, y\right\rangle & \geq\left\langle x-z_{n_{i}}, A x\right\rangle \\
& \geq\left\langle x-z_{n_{i}}, A x\right\rangle-\left\langle x-z_{n_{i}} \frac{z_{n_{i}}-v_{n_{i}}}{r_{n_{i}}}+A v_{n_{i}}\right\rangle \\
& \geq\left\langle x-z_{n_{i}}, A x-A z_{n_{i}}\right\rangle+\left\langle x-z_{n_{i}}, A z_{n_{i}}-A v_{n_{i}}\right\rangle-\left\langle x-z_{n_{i^{\prime}}} \frac{z_{n_{i}}-v_{n_{i}}}{r_{n_{i}}}\right\rangle \\
& \geq\left\langle x-z_{n_{i}}, A z_{n_{i}}-A v_{n_{i}}\right\rangle-\left\langle x-z_{n_{i}}, \frac{z_{n_{i}}-v_{n_{i}}}{r_{n_{i}}}\right\rangle .
\end{aligned}
$$

In view of the restriction (b), we obtain from (3.13) that $\langle x-q, y\rangle \geq 0$. We have $q \in$ $A^{-1} 0$ and hence $q \in V I(C, A)$.

Next, we prove that $q \in(B+M)^{-1}(0)$. Notice that

$$
x_{n}-s_{n} B x_{n} \in v_{n}+s_{n} M v_{n}
$$

that is,

$$
\frac{x_{n}-v_{n}}{s_{n}}-B x_{n} \in M v_{n}
$$

Let $\mu \in v$. Since $M$ is monotone, we find from (3.18) that

$$
\left\langle\frac{x_{n}-v_{n}}{s_{n}}-B x_{n}-\mu, v_{n}-v\right\rangle \geq 0 .
$$

In view of the restriction (c), we see from (3.10) that

$$
\langle-B q-\mu, q-v\rangle \geq 0 \text {. }
$$

This implies that $-B q \in M q$, that is, $q \in(B+M)^{-1}(0)$. This completes $q \in \mathcal{F}$. Assume that there exists another subsequence $\left\{x_{n_{i}}\right\}$ of $\left\{x_{n}\right\}$ weak converges weakly to $q^{\prime} \in \mathcal{F}$. We can easily conclude from Opial's condition (see [49]) that $q=q^{\prime}$.

Finally, we show that $q=\operatorname{Proj}_{\mathcal{F}} x_{1}$ and $\left\{x_{n}\right\}$ converges strongly to $q$. This completes the proof of Theorem 3.1. In view of the weak lower semicontinuity of the norm, we obtain from (3.5) that

$$
\begin{aligned}
\left\|x_{1}-\operatorname{Proj}_{\mathcal{F}} x_{1}\right\| & \leq\left\|x_{1}-q\right\| \leq \liminf _{n \rightarrow \infty}\left\|x_{1}-x_{n}\right\| \\
& \leq \limsup _{n \rightarrow \infty}\left\|x_{1}-x_{n}\right\| \leq\left\|x_{1}-\operatorname{Proj}_{\mathcal{F}} x_{1}\right\|
\end{aligned}
$$

which yields that $\lim _{n \rightarrow \infty}\left\|x_{1}-x_{n}\right\|=\left\|x_{1}-\operatorname{Proj}_{\mathcal{F}} x_{1}\right\|=\left\|x_{1}-q\right\|$. It follows that $\left\{x_{n}\right\}$ converges strongly to $\operatorname{Proj}_{\mathcal{F}} x_{1}$. This completes the proof.

We conclude from Theorem 3.1 the following results on nonexpansive mappings.

Corollary 3.2. Let $C$ be a nonempty, closed, and convex subset of $H$. Let $S: C \rightarrow C$ be a nonexpansive mapping with a nonempty fixed point set, $A: C \rightarrow H$ be an $\alpha$-inverse- 
strongly monotone mapping, and $B: C \rightarrow H$ be a $\beta$-inverse-strongly monotone mapping. Let $M: H \rightrightarrows H$ be a maximal monotone operator such that $D(M) \subset C$. Assume that $\mathcal{F}:=F(S) \cap(B+M)^{-1}(0) \cap V I(C, A)$ is not empty. Let $\left\{x_{n}\right\}$ be a sequence generated by the following iterative process:

$$
\left\{\begin{array}{l}
x_{1} \in C \\
C_{1}=C \\
\left.z_{n}=\operatorname{Proj}_{C}\left(J_{s_{n}} x_{n}-s_{n} B x_{n}\right)-r_{n} A J_{s_{n}}\left(x_{n}-s_{n} B x_{n}\right)\right) \\
y_{n}=\alpha_{n} x_{n}+\left(1-\alpha_{n}\right) S z_{n} \\
C_{n+1}=\left\{v \in C_{n}:\left\|y_{n}-v\right\| \leq\left\|x_{n}-v\right\|\right\} \\
x_{n+1}=\operatorname{Proj}_{C_{n+1}} x_{1}, \quad n \geq 0
\end{array}\right.
$$

where $J_{s_{n}}=\left(I+s_{n} M\right)^{-1},\left\{r_{n}\right\}$ is a sequence in $(0,2 \alpha),\left\{s_{n}\right\}$ is a sequence in $(0,2 \beta)$, and $\left\{\alpha_{n}\right\}$ is a sequence in $(0,1)$. Assume that the following restrictions are satisfied

(a) $0 \leq \alpha_{n} \leq a<1$;

(b) $0<r \leq r_{n} \leq r^{\prime}<2 \alpha$;

(c) $0<s \leq s_{n} \leq s^{\prime}<2 \beta$,

where $a, r, r^{\prime}, s$, and s' are real constants. Then the sequence $\left\{x_{n}\right\}$ converges strongly to $\operatorname{Proj}_{\mathcal{F}} x_{1}$.

If $A=0$, then Corollary 3.2 is reduced to the following.

Corollary 3.3. Let $C$ be a nonempty, closed, and convex subset of $H$. Let $S: C \rightarrow C$ be a nonexpansive mapping with a nonempty fixed point set, and $B: C \rightarrow H$ be a $\beta$ inverse-strongly monotone mapping. Let $M: H \rightrightarrows H$ be a maximal monotone operator such that $D(M) \subset C$. Assume that $\mathcal{F}:=F(S) \cap(B+M)^{-1}(0)$ is not empty. Let $\left\{x_{n}\right\}$ be a sequence generated by the following iterative process:

$$
\left\{\begin{array}{l}
x_{1} \in C, \\
C_{1}=C \\
y_{n}=\alpha_{n} x_{n}+\left(1-\alpha_{n}\right) S J_{s_{n}}\left(x_{n}-s_{n} B x_{n}\right), \\
C_{n+1}=\left\{v \in C_{n}:\left\|y_{n}-v\right\| \leq\left\|x_{n}-v\right\|\right\}, \\
x_{n+1}=\operatorname{Proj}_{C_{n+1}} x_{1}, \quad n \geq 0,
\end{array}\right.
$$

where $J_{s_{n}}=\left(I+s_{n} M\right)^{-1}\left\{s_{n}\right\}$ is a sequence in $(0,2 \beta)$, and $\left\{\alpha_{n}\right\}$ is a sequence in $(0,1)$. Assume that the following restrictions are satisfied

(a) $0 \leq \alpha_{n} \leq a<1$;

(b) $0<s \leq s_{n} \leq s^{\prime}<2 \beta$,

where $a, s$, and s' are real constants. Then the sequence $\left\{x_{n}\right\}$ converges strongly to $\operatorname{Proj}_{\mathcal{F}} x_{1}$.

If $B=0$, then Corollary 3.2 is reduced to the following.

Corollary 3.4. Let $C$ be a nonempty, closed, and convex subset of $H$. Let $S: C \rightarrow C$ be a nonexpansive mapping with a nonempty fixed point set, $A: C \rightarrow H$ a $\alpha$-inverse- 
strongly monotone mapping. Let $M: H \rightrightarrows H$ be a maximal monotone operator such that $D(M) \subset C$. Assume that $\mathcal{F}:=F(S) \cap M^{-1}(0) \cap V I(C, A)$ is not empty. Let $\left\{x_{n}\right\}$ be a sequence generated by the following iterative process:

$$
\left\{\begin{array}{l}
x_{1} \in C, \\
C_{1}=C, \\
\left.z_{n}=\operatorname{Proj}_{C}\left(J_{s_{n}} x_{n}-r_{n} A J_{s_{n}} x_{n}\right)\right), \\
y_{n}=\alpha_{n} x_{n}+\left(1-\alpha_{n}\right) S z_{n}, \\
C_{n+1}=\left\{v \in C_{n}:\left\|y_{n}-v\right\| \leq\left\|x_{n}-v\right\|\right\}, \\
x_{n+1}=\operatorname{Proj}_{C_{n+1}} x_{1}, \quad n \geq 0,
\end{array}\right.
$$

where $J_{s_{n}}=\left(I+s_{n} M\right)^{-1},\left\{r_{n}\right\}$ is a sequence in $(0,2 \alpha),\left\{s_{n}\right\}$ is a sequence in $(0,+\infty)$, and $\left\{\alpha_{n}\right\}$ is a sequence in $(0,1)$. Assume that the following restrictions are satisfied

(a) $0 \leq \alpha_{n} \leq a<1$;

(b) $0<r \leq r_{n} \leq r^{\prime}<2 \alpha$;

(c) $0<s \leq s_{n}<\infty$,

where $a, r, r$, and s are real constants. Then the sequence $\left\{x_{n}\right\}$ converges strongly to $\operatorname{Proj}_{\mathcal{F}} x_{1}$.

Let $f: H \rightarrow(-\infty,+\infty]$ be a proper convex lower semicontinuous function. Then the subdifferential $\partial$ of $f$ is defined as follows

$$
\partial f(x)=\{y \in H: f(z) \geq f(x)+\langle z-x, y\rangle, \quad z \in H\}, \quad \forall x \in H .
$$

From Rockafellar [50], we know that $\partial f$ is maximal monotone. It is not hard to verify that $0 \in \partial f(x)$ if and only if $f(x)=\min _{y \in H} f(y)$.

Let $I_{C}$ be the indicator function of $C$, i.e.,

$$
I_{C}(x)= \begin{cases}0, & x \in C \\ +\infty, & x \notin C\end{cases}
$$

Since $I_{C}$ is a proper lower semicontinuous convex function on $H$, we see that the subdifferential $\partial I_{C}$ of $I_{C}$ is a maximal monotone operator. It is clearly that $J_{S} x=\operatorname{Proj}_{C} x$, $\forall x \in H$. Notice that $\left(B+\partial I_{C}\right)^{-1}(0)=V I(C, B)$. Indeed,

$$
\begin{aligned}
x \in\left(B+\partial I_{C}\right)^{-1}(0) & \Leftrightarrow 0 \in B x+\partial I_{C} x \\
& \Leftrightarrow-B_{X} \in \partial I_{C} x \\
& \Leftrightarrow\langle B x, y-x\rangle \geq 0 \\
& \Leftrightarrow x \in V I(C, B) .
\end{aligned}
$$

In view of Theorem 3.1, we have the following.

Corollary 3.5. Let $C$ be a nonempty, closed, and convex subset of $H$. Let $S: C \rightarrow C$ be $a \alpha \kappa$-strict pseudocontraction with a nonempty fixed point set, $A: C \rightarrow H$ be an $\alpha$ inverse-strongly monotone mapping, and $B: C \rightarrow H$ be a $\beta$-inverse-strongly monotone mapping. Assume hat $\mathcal{F}:=F(S) \cap \operatorname{VI}(C, B) \cap \operatorname{VI}(C, A)$ is not empty. Let $\left\{x_{n}\right\}$ be a sequence generated by he following iterative process: 


$$
\left\{\begin{array}{l}
x_{1} \in C \\
C_{1}=C \\
z_{n}=\operatorname{Proj}_{C}\left(\operatorname{Proj}_{C}\left(x_{n}-s_{n} B x_{n}\right)-r_{n} A \operatorname{Proj}_{C}\left(x_{n}-s_{n} B x_{n}\right)\right) \\
y_{n}=\alpha_{n} x_{n}+\left(1-\alpha_{n}\right)\left(\beta_{n} z_{n}+\left(1-\beta_{n}\right) S z_{n}\right) \\
C_{n+1}=\left\{v \in C_{n}:\left\|y_{n}-v\right\| \leq\left\|x_{n}-v\right\|\right\} \\
x_{n+1}=\operatorname{Proj}_{C_{n+1}} x_{1}, \quad n \geq 0
\end{array}\right.
$$

where $\left\{r_{n}\right\}$ is a sequence in $(0,2 \alpha),\left\{s_{n}\right\}$ is a sequence in $(0,2 \beta)$, and $\left\{\alpha_{n}\right\}$ and $\left\{\beta_{n}\right\}$ are sequences in $(0,1)$. Assume that the following restrictions are satisfied

(a) $0 \leq \alpha_{n} \leq a<1, \kappa \leq \beta_{n} \leq b<1$;

(b) $0<r \leq r_{n} \leq r^{\prime}<2 \alpha$;

(c) $0<s \leq s_{n} \leq s^{\prime}<2 \beta$,

where $a, b, r, r, s$, and s' are real constants. Then the sequence $\left\{x_{n}\right\}$ converges strongly to $\operatorname{Pr} \operatorname{oj}_{\mathcal{F}} x_{1}$.

\section{Applications}

Let $F$ be a bifunction of $C \times C$ into $\mathbb{R}$, where $\mathbb{R}$ denotes the set of real numbers. Recall the following equilibrium problem in the terminology of Blum and Oettli [51] (see also Fan [52]).

Find $x \in C$ such that $F(x, y) \geq 0, \quad \forall y \in C$.

To study the equilibrium problem (4.1), we may assume that $F$ satisfies the following conditions:

(A1) $F(x, x)=0$ for all $x \in C$;

(A2) $F$ is monotone, i.e., $F(x, y)+F(y, x)=0$ for all $x, y \in C$;

(A3) for each $x, y, z \in C$,

$$
\limsup _{t \downarrow 0} F(t z+(1-t) x, y) \leq F(x, y) ;
$$

(A4) for each $x \in C, y \mapsto F(x, y)$ is convex and lower semi-continuous.

Putting $F(x, y)=\langle A x, y-x\rangle$ for every $x, y \in C$, we see that the equilibrium problem (4.1) is reduced to the variational inequality (2.1).

The following lemma can be found in $[51,53]$.

Lemma 4.1. Let $C$ be a nonempty, closed, and convex subset of $H$ and $F: C x C \rightarrow \mathbb{R} a$ bifunction satisfying (A1)-(A4). Then, for any $s>0$ and $x \in H$, there exists $z \in C$ such that

$$
F(z, y)+\frac{1}{s}\langle y-z, z-x\rangle \geq 0, \quad \forall y \in C .
$$

Further, define

$$
T_{s} x=\left\{z \in C: F(z, y)+\frac{1}{s}\langle y-z, z-x\rangle \geq 0, \quad \forall y \in C\right\}
$$

for all $s>0$ and $x \in H$. Then, the following hold:

(a) $T_{s}$ is single-valued; 
(b) $T_{s}$ is firmly nonexpansive; that is,

$$
\left\|T_{s} x-T_{s} y\right\|^{2} \leq\left\langle T_{s} x-T_{s} y, x-y\right\rangle, \quad \forall x, y \in H ;
$$

(c) $F\left(T_{s}\right)=E P(F)$;

(d) $E P(F)$ is closed and convex.

Lemma 4.2 [8]. Let $C$ be a nonempty, closed, and convex subset of $H, F$ a bifunction from $C \times C$ to $\mathbb{R}$ which satisfies (A1)-(A4), and $A_{F}$ a multivalued mapping of $H$ into itself defined by

$$
A_{F^{x}}=\left\{\begin{array}{lr}
\{z \in H: F(x, y) \geq\langle y-x, z\rangle, \forall y \in C\}, & x \in C, \\
\emptyset, & x \notin C .
\end{array}\right.
$$

Then $A_{F}$ is a maximal monotone operator with the domain $D\left(A_{F}\right) \subset C$, $E P(F)=A_{F}^{-1}(0)$, where $F P(F)$ stands for the solution set of (4.1), and

$$
T_{s} x=\left(I+s A_{F}\right)^{-1} x, \quad \forall x \in H, r>0,
$$

where $T_{s}$ is defined as in (4.2).

In this section, we consider the problem of approximating a solution of the equilibrium problem.

Theorem 4.3. Let $C$ be a nonempty, closed, and convex subset of $H$. Let $S: C \rightarrow C$ be a $\kappa$-strict pseudocontraction with a nonempty fixed point set, and $F: C \times C \rightarrow \mathbb{R}$ a bifunction satisfying (A1)-(A4). Assume that $\mathcal{F}:=F(S) \cap E P(F)$ is not empty. Let $\left\{x_{n}\right\}$ be a sequence generated by the following iterative process:

$$
\left\{\begin{array}{l}
x_{1} \in C \\
C_{1}=C \\
y_{n}=\alpha_{n} x_{n}+\left(1-\alpha_{n}\right)\left(\beta_{n}\left(I+s_{n} A_{F}\right)^{-1} x_{n}+\left(1-\beta_{n}\right) S\left(I+s_{n} A_{F}\right)^{-1} x_{n}\right), \\
C_{n+1}=\left\{v \in C_{n}:\left\|y_{n}-v\right\| \leq\left\|x_{n}-v\right\|\right\} \\
x_{n+1}=\operatorname{Proj}_{C_{n+1}} x_{1}, \quad n \geq 0
\end{array}\right.
$$

where $A_{F}$ is defined by (4.3), $\left\{s_{n}\right\}$ is a positive sequence, and $\left\{\alpha_{n}\right\}$ and $\left\{\beta_{n}\right\}$ are sequences in $(0,1)$. Assume that the following restrictions are satisfied

(a) $0 \leq \alpha_{n} \leq a<1, \kappa \leq \beta_{n} \leq b<1$;

(b) $0<s \leq s_{n} \leq s^{\prime}<\infty$,

where $a, b, s$, and s' are real constants. Then the sequence $\left\{x_{n}\right\}$ converges strongly to $\operatorname{Proj}_{\mathcal{F}} x_{1}$.

Proof. Putting $A=B=0$, we immediately conclude from Lemmas 4.1 and 4.2 the desired conclusion. 


\section{Authors' contributions}

CW designed and performed all the steps of proof in this research and also wrote the paper. AL participated in the design of the study. All authors read and approved the final manuscript.

\section{Competing interests}

The authors declare that they have no competing interests.

Received: 25 January 2012 Accepted: 24 May 2012 Published: 24 May 2012

\section{References}

1. Burachik, RS, lusem, AN, Svaiter, BF: Enlargements of maximal monotone operators with applications to variational inequalities. Set-valued Anal. 5, 159-180 (1997). doi:10.1023/A:1008615624787

2. Revalski, JP, Théra, A: Enlargements and sums of monotone operators. Nonlinear Anal. , 48:: 505-519 (2002)

3. Svaiter, BF, Burachik, RS: $\varepsilon$-enlargements of maximal monotone operators in Banach spaces. Set-Valued Anal. 7, 117-132 (1999). do: 10.1023/A:1008730230603

4. Moudafi, A: On the regularization of the sum of two maximal monotone operators. Nonlinear Anal. 42, 1203-1208 (2000). doi:10.1016/50362-546X(99)00136-4

5. Moudafi, A, Oliny, M: Convergence of a splitting inertial proximal method for monotone operators. J Comput Appl Math. 155, 447-454 (2003). doi:10.1016/50377-0427(02)00906-8

6. Zhang, SS, Lee, JHW, Chan, CK: Algorithms of common solutions for quasi variational inclusion and fixed point problems. Appl Math Mech. 29, 571-581 (2008). doi:10.1007/s10483-008-0502-y

7. Qin, X, Kang, Jl, Cho, YJ: On quasi-variational inclusions and asymptotically strict pseudo-contractions. J Nonlinear Convex Anal. 11, 441-453 (2010)

8. Takahashi, S, Takahashi, W, Toyoda, M: Strong convergence theorems for maximal monotone operators with nonlinear mappings in Hilbert spaces. J Optim Theory Appl. 147, $27-41$ (2010). doi:10.1007/s10957-010-9713-2

9. Qin, X, Cho, SY, Kang, SM: Iterative algorithms for variational inequality and equilibrium problems with applications. J Global Optim. 48, 423-445 (2010). doi:10.1007/s10898-009-9498-8

10. Korpelevich, GM: An extragradient method for finding saddle points and for other problems. Ekonomika i Matematicheskie Metody. 12, 747-756 (1976)

11. Yang, S, Li, W: Iterative solutions of a system of equilibrium problems in Hilbert spaces. Adv Fixed Point Theory. 1, 15-26 (2011)

12. Nadezhkina, $\mathrm{N}$, Takahashi, W: Weak convergence theorem by an extragradient method for nonexpansive mappings and monotone mappings. J Optim Theory Appl. 128, 191-201 (2006). doi:10.1007/s10957-005-7564-z

13. Qin, $X, S u, Y$, Shang, M: Strong convergence of a general iterative algorithm for equilibrium problems and variational inequality problems. Math Comput Model. 48, 1033-1046 (2008). doi:10.1016/j.mcm.2007.12.008

14. Kim, JK: Strong convergence theorems by hybrid projection methods for equilibrium problems and fixed point problems of the asymptotically quasi-囚-nonexpansive mappings. Fixed Point Theory Appl 2011. 10 (2011)

15. Kim, JK, Cho, SY, Qin, X: Some results on generalized equilibrium problems involving strictly pseudocontractive mappings. Acta Mathematica Scientia. 31, 2041-2057 (2011). doi:10.1016/S0252-9602(11)60380-9

16. Kim, JK, Cho, SY, Qin, X: Hybrid projection algorithms for generalized equilibrium problems and strictly pseudocontractive mappings. J Inequal Appl 2010, 18 (2010). (Article ID 312602)

17. Ye, J, Huang, J: Strong convergence theorems for fixed point problems and generalized equilibrium problems of three relatively quasi-nonexpansive mappings in Banach spaces. J Math Comput Sci. 1, 1-18 (2011)

18. Qin, X, Cho, YJ, Kang, SM: Convergence theorems of common elements for equilibrium problems and fixed point problems in Banach spaces. J Comput Appl Math. 225, 20-30 (2009). doi:10.1016/j.cam.2008.06.011

19. Lv, S: Generalized systems of variational inclusions involving (A, $\eta$ )-monotone mappings. Adv Fixed Point Theory. 1 , $1-14(2011)$

20. Kang, SM, Cho, SY, Liu, Z: Convergence iterative sequences for generalized equilibrium problems involving inversestrongly monotone mappings. J Inequal Appl. 2010, 827082 (2010)

21. Qin, X, Cho, SY, Kang, SM: Strong convergence of shrinking projection methods for quasi-ख-nonexpansive mappings and equilibrium problems. J Comput Appl Math. 234, 750-760 (2010). doi:10.1016/j.cam.2010.01.015

22. Chang, SS, Lee, HWJ, Chan, CK: A new method for solving equilibrium problem fixed point problem and variational inequality problem with application to optimization. Nonlinear Anal. 70, 3307-3319 (2009). doi:10.1016/j.na.2008.04.035

23. Chang, SS, Lee, HWJ, Chan, CK: A new hybrid method for solving a generalized equilibrium problem, solving a variational inequality problem and obtaining common fixed points in Banach spaces with applications. Nonlinear Anal. 73, 2260-2270 (2010). doi:10.1016/j.na.2010.06.006

24. Qin, X, Chang, SS, Cho, YJ: Iterative methods for generalized equilibrium problems and fixed point problems with applications. Nonlinear Anal Real World Appl. 11, 2963-2972 (2010). doi:10.1016/j.nonrwa.2009.10.017

25. Qin, X, Cho, SY, Kang, SM: Convergence of an iterative algorithm for systems of variational inequalities and nonexpansive mappings. J Comput Appl Math. 233, 231-240 (2009). doi:10.1016/j.cam.2009.07.018

26. Shehu, Y: A new iterative scheme for a countable family of relatively nonexpansive mappings and an equilibrium problem in Banach spaces. J Global Optim. doi:10.1007/s10898-011-9775-1

27. Saewan, S, Kumam, P: Modified hybrid block iterative algorithm for convex feasibility problems and generalized equilibrium problems for uniformly quasi-囚-asymptotically nonexpansive mappings. Abstr Appl Anal 22 (2010). (Article ID 357120)

28. Qin, X, Cho, YJ, Kang, SM: Viscosity approximation methods for generalized equilibrium problems and fixed point problems with applications. Nonlinear Anal. 72, 99-112 (2010). doi:10.1016/j.na.2009.06.042

29. Polyak, BT: Introduction to optimization, Optimization Software. Princeton Hall, New York. (1987)

30. Calamai, PH, Moré, Jj: Projected gradient methods for linearly constrained problems. Math Program. 39, 93-116 (1987). doi:10.1007/BF02592073

31. Levitin, ES, Polyak, BT: Constrained minimization methods. Zh Vychisl Mat Mat Fiz. 6, 787-823 (1966) 
32. Byrne, B: A unified treatment of some iterative algorithms in signal processing and image reconstruction. Inverse Probl. 20, 103-120 (2008)

33. Censor, Y, Elfving, T, Kopf, N, Bortfeld, T: The multiple-sets split feasibility problem and its applications for inverse problems. Inverse Probl. 21, 2071-2084 (2005). doi:10.1088/0266-5611/21/6/017

34. Censor, Y, Bortfeld, T, Martin, B, Trofimov, A: A unified approach for inversion problems in intensity-modulated radiation therapy. Phys Med Biol. 51, 2353-2365 (2006). doi:10.1088/0031-9155/51/10/001

35. Lopez, G, Martin, V, Xu, HK: Perturbation techniques for nonexpansive mappings with applications. Nonlinear Anal. 10 2369-2383 (2009). doi:10.1016/j.nonrwa.2008.04.020

36. Browder, FE: Nonexpansive nonlinear operators in a Banach space. Proc Nat Acad Sci USA. 54, 1041-1044 (1965). doi:10.1073/pnas.54.4.1041

37. liduka, $\mathrm{H}$, Takahashi, W: Strong convergence theorems for nonexpansive mappings and inverse-strongly monotone mappings. Nonlinear Anal. 61, 341-350 (2005). doi:10.1016/j.na.2003.07.023

38. Qin, X, Su, Y: Approximation of a zero point of accretive operator in Banach spaces. J Math Anal Appl. 329, 415-424 (2007). doi:10.1016/j.jmaa.2006.06.067

39. Cho, YJ, Qin, X, Kang, Jl: Convergence theorems based on hybrid methods for generalized equilibrium problems and fixed point problems. Nonlinear Anal. 71, 4203-4214 (2009). doi:10.1016/j.na.2009.02.106

40. Takahashi, W, Toyoda, M: Weak convergence theorems for nonexpansive mappings and monotone mappings. J Optim Theory Appl. 118, 417-428 (2003). doi:10.1023/A:1025407607560

41. Cho, YJ, Kang, SM, Zhou, H: Approximate proximal point algorithms for finding zeroes of maximal monotone operators in Hilbert spaces. J Inequal Appl. 2008, 598191 (2008)

42. Eckstein, J: Nonlinear proximal point algorithms using Bregman functions, with applications to convex programming. Math Oper Res. 18, 202-226 (1993). doi:10.1287/moor.18.1.202

43. Matsushita, SY, Takahashi, W: Existence theorems for set-valued operators in Banach spaces. Set-Valued Anal. 15 251-264 (2007). doi:10.1007/s11228-006-0030-8

44. Solodov, MV, Svaiter, FF: A hybrid projection-proximal point algorithm. J Convex Anal. 6, $59-70$ (1999)

45. Qin, X, Cho, YJ, Kang, SM: Approximating zeros of monotone operators by proximal point algorithms. J Glob Optim. 46, 75-87 (2010). doi:10.1007/s10898-009-9410-6

46. Zhou, H: Convergence theorems of fixed points for $\mathrm{k}$-strict pseudo-contractions in Hilbert spaces. Non-linear Anal. 69, 456-462 (2008)

47. Browder, FE: Nonlinear operators and nonlinear equations of evolution in Banach spaces. Proc Symp Pure Math. 18, 78-81 (1976)

48. Rockafellar, RT: On the maximality of sums of nonlinear monotone operators. Trans Am Math Soc. 149, 75-88 (1970). doi:10.1090/S0002-9947-1970-0282272-5

49. Opial, Z: Weak convergence of the sequence of successive approximation for nonexpansive mappings. Bull Am Math Soc. 73, 591-597 (1967). doi:10.1090/50002-9904-1967-11761-0

50. Rockafellar, RT: Characterization of the subdifferentials of convex functions. Pac J Math. 17, 497-510 (1996)

51. Blum, E, Oettli, W: From optimization and variational inequalities to equilibrium problems. Math Stud. 63, 123-145 (1994)

52. Fan, K: A minimax inequality and applications. In: Shisha (ed.) Inequality III. pp. 103-113. Academic Press, New york (1972)

53. Combettes, PL, Hirstoaga, SA: Equilibrium programming in Hilbert spaces. J Nonlinear Convex Anal. 6, 117-136 (2005)

doi:10.1186/1687-1812-2012-90

Cite this article as: Wu and Liu: Strong convergence of a hybrid projection iterative algorithm for common solutions of operator equations and of inclusion problems. Fixed Point Theory and Applications 2012 2012:90.

\section{Submit your manuscript to a SpringerOpen ${ }^{\circ}$ journal and benefit from:}

- Convenient online submission

Rigorous peer review

- Immediate publication on acceptance

- Open access: articles freely available online

- High visibility within the field

- Retaining the copyright to your article

Submit your next manuscript at $\gg$ springeropen.com 